\title{
Effect of thrombolysis on the evolution of late potentials within 10 days of infarction
}

Michael Eldar, Jonathan Leor, Hanoch Hod, Zeev Rotstein, Smadar Truman, Eliezer Kaplinsky, Shimon Abboud

\begin{abstract}
Patients with late potentials in the signal averaged electrocardiogram are more at risk of lethal arrhythmias in the period after acute myocardial infarction. To test the effects of thrombolysis on the incidence and evolution of late potentials, 158 consecutive patients were prospectively studied during the first 10 days after acute myocardial infarction. The study population consisted of two groups: 93 control patients treated conservatively and 65 patients treated with intravenous thrombolysis. Recordings of signal averaged electrocardiogram were obtained within two days and 7-10 days after infarction. The incidence of late potentials in the first two days after infarction was not significantly different in the thrombolytic and control groups (14\% $v$ $11 \cdot 8 \%$ ). By 7-10 days the incidence of late potentials among patients who underwent thrombolysis remained unchanged (14\%); however, it increased significantly in the control group $(11.8 \%$ to $22.5 \%)$.

Thus thrombolysis seems to reduce the evolution of late potentials within 10 days of infarction. Because the risk of fatal arrhythmias is higher in patients with late potentials this study may partly explain the reduced mortality after thrombolysis.
\end{abstract}

Ventricular late potentials consist of low amplitude high frequency electrical signals that occur at the end of the QRS complex or during the ST segment. These signals probably arise from areas of slow conduction in diseased myocardial regions and may thus be markers of arrhythmogenic features. ${ }^{1}$ Late potentials present within 1-4 weeks after acute myocardial infarction predicted a higher risk of sudden cardiac death and ventricular tachycardia in the next 6-24 months. ${ }^{2}$ Recently, thrombolytic treatment within a few hours of acute myocardial infarction has been established as an effective means of improving survival ${ }^{34}$ and preserving myocardial function ${ }^{56}$ in the acute and chronic phases of infarction. However, there are few data on the incidence, course, and the effects of thrombolysis on late potentials in the early post-infarction period. We have evaluated the effects of thrombolytic treatment on the incidence and evolution of late potentials during the first 10 days after acute myocardial infarction.

\section{Patients and methods}

Our prospective study included 158 consecutive patients with first acute myocardial infarction who underwent two signal averaged electrocardiogram recordings, the first within two days and the second within 7-10 days of the acute myocardial infarction. We excluded patients with a QRS complex lasting $\geqslant 110 \mathrm{~ms}$ or atrial fibrillation on an admission surface electrocardiogram. There were 138 men and 20 women (mean (SD) age 60 (8) years). Anterior acute myocardial infarction was diagnosed in 60 and inferior acute myocardial infarction in 98 patients. The diagnosis of acute myocardial infarction was based on prolonged ( $>30 \mathrm{~min}$ utes) chest pain, $S T$ elevation of $\geqslant 1 \mathrm{mV}$ in at least two leads on the admission electrocardiogram, and a raised serum concentration of creatine kinase of myocardial origin.

Intravenous thrombolytic agents were given to 65 patients within four hours of the acute myocardial infarction: 24 were treated with streptokinase (1.5 million units) and 41 with tissue plasminogen activator $(120 \mathrm{mg}$ ) (thrombolysis group). In 49 patients reperfusion was successful and in 16 it was not. Successful reperfusion was defined as an abrupt decrease in chest pain and a decrease of ST segment elevation by at least $50 \%$ within 30 minutes of administration of the thrombolytic agent associated with early peaking of creatine kinase MB (within 9-12 hours). Ninety three patients did not receive thrombolytic agents (control group) either because they arrived too late at the hospital (chest pain for more than four hours) or because of conventional contraindications to thrombolytic treatment. The mean (SD) left ventricular ejection fraction determined 2-10 days after infarction by the multiple gated acquisition technique was significantly higher in successful reperfusion than unsuccessful reperfusion and control patients $(57 \cdot 4(10 \cdot 1) \%$ v $42.3(14 \cdot 7) \%$ and $42.3(15) \%$, respectively, $\mathrm{p}<0.05)$. No other clinical variables were significantly different among the groups (table 1).

Signal averaging was obtained by the Hypec analyser (Aerotel, Israel), which allows separate averaging of the 12 electrocardiographic leads. The system uses a non-recursive (finite impulse response) digital filter provided by fast Fourier transformation algorithm which allows for a zero phase delay and prevention of the ringing phenomenon without the use of bidirectional signal processing. ${ }^{7}$ Normal values for signal averaged electrocardiogram were measured in 25 normal subjects, 22 
Table 1 Clinical variables of the study groups

\begin{tabular}{|c|c|c|c|}
\hline \multirow[b]{2}{*}{ Variable } & \multicolumn{2}{|l|}{ Thrombolysis } & \multirow[b]{2}{*}{ Control } \\
\hline & Successful & Unsuccessful & \\
\hline $\begin{array}{l}\text { Patients } \\
\text { Age (mean (SD)) } \\
\text { Men } \\
\text { Women } \\
\text { Anterior MI } \\
\text { Inferior MI } \\
\text { LVEF \% (mean (SD)) }\end{array}$ & $\begin{array}{ll}49 & \\
58 \cdot 6 & (10) \\
42 & \\
7 & \\
21 & \\
28 & \\
57 \cdot 4 & (10 \cdot 1)\end{array}$ & $\begin{array}{cc}16 & \\
61 & (6 \cdot 25) \\
15 & \\
1 & \\
8 & \\
8 & \\
42 \cdot 3 & (14 \cdot 7)\end{array}$ & $\begin{array}{ll}93 & \\
61 & (9) \\
81 & \\
12 & \\
31 & \\
62 & \\
42 \cdot 3 & (15 \cdot 0)\end{array}$ \\
\hline
\end{tabular}

LVEF, left ventricular ejection fraction; MI, myocardial infarction.

patients after infarction, and 14 patients with ventricular tachycardia or fibrillation after infarction. Accordingly, late potentials were defined as filtered $(60-200 \mathrm{~Hz})$ QRS complexes lasting $\geqslant 110 \mathrm{~ms}$ with a root mean square voltage in the last 40 ms of the QRS complex $\left(\mathrm{RMS}_{40}\right)$ of $\leqslant 10 \mu \mathrm{V}$ in at least two adjacent electrocardiographic leads.

We used the McNemar test for significance of changes ${ }^{8}$ for statistical analysis of the difference between the occurrence of late potentials on the first and subsequent signal averaged electrocardiograms. The Mann-Whitney $U$ test was used to compare the distribution of QRS duration and $R M S_{40}$ in both groups.

\section{Results}

Table 2 shows the frequency of late potentials. Figures 1 and 2 show signal averaged electrocardiograms with and without late potentials.

The mean (SD) duration of the QRS complex was significantly shorter after successful reperfusion than in the control group in seven out of 12 leads recorded within two days (for example in lead II 96 (8) $v 101$ (13) ms, p < 0.05 ) and in 10 of 12 leads within 7-10 days (for example in lead II 99 (8) $v 106(19) \mathrm{ms}, \mathrm{p}<$ $0 \cdot 05)$. There were no significant differences in
Table 2 Frequency of late potentials in thrombolysis and control groups

\begin{tabular}{lrlrl}
\hline Treatment & $\begin{array}{l}2 \text { days } \\
n(\%)\end{array}$ & \multicolumn{2}{l}{$\begin{array}{l}7-10 \text { days } \\
n(\%)\end{array}$} \\
\hline Thrombolysis: & $9 / 64$ & $(14)$ & $9 / 64$ & $(14)$ \\
$\quad$ Total & $5 / 49$ & $(10 \cdot 4)$ & $5 / 49$ & $(10 \cdot 4)$ \\
Successful & $4 / 16$ & $(25)$ & $4 / 16$ & $(25)$ \\
Unsuccessful & $11 / 93$ & $(11 \cdot 8)$ & $21 / 93$ & $(22 \cdot 5)$ \\
Control: & & & \\
$\quad$ Total & & &
\end{tabular}

$\mathrm{RMS}_{40}$ between the groups. For example, in lead II $\mathrm{RMS}_{40}$ was 19 (10) $v 21$ (14) $\mu \mathrm{V}$ within two days and $20(10) v 19(13) \mu \mathrm{V}$ within $7-10$ days in the successful reperfusion and control groups respectively. No significant differences in QRS duration and $R M S_{40}$ were found between patients in whom thrombolysis was unsuccessful and the controls.

In the first signal averaged electrocardiogram (recorded within two days of infarction) the frequency of late potentials was similar in the thrombolysis and control groups (14.0\% and $11.8 \%$ respectively). In the second signal averaged electrocardiogram (recorded within 7-10 days) there was a significant increase in the frequency of late potentials among control patients (from $11.8 \%$ to $22.5 \%$, p $<0.01$ ), whereas the frequency of late potentials in the thrombolysis group remained at $14 \%$. In patients showing successful reperfusion late potentials disappeared in two patients in the second signal averaged electrocardiogram while in two other patients late potentials were detected for the first time in the second (7-10 days) signal averaged electrocardiogram recording. In patients in whom reperfusion was unsuccessful and in control patients late potentials recorded within two days were still present in the signal averaged electrocardiogram performed 7-10 days after the acute myocardial infarction. The difference in the frequency of
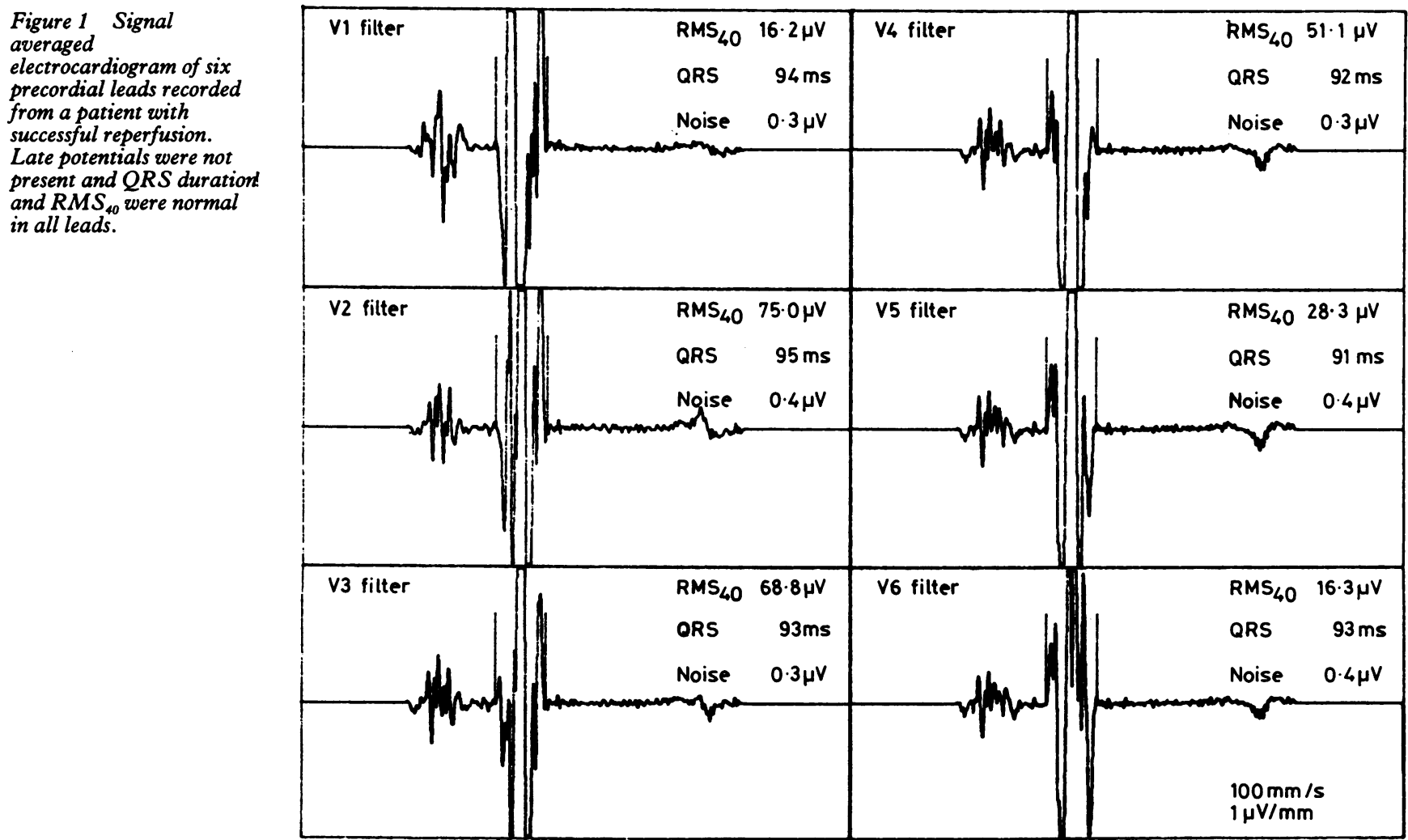
Figure 2 Signal averaged

electrocardiogram of six precordial leads in a patient who was not treated with thrombolytic agents. Late potentials are clearly detected at the end of the filtered $Q R S$ complexes. The abnormally long $O R S$ duration and low $R M S_{40}$ values are given for each lead.

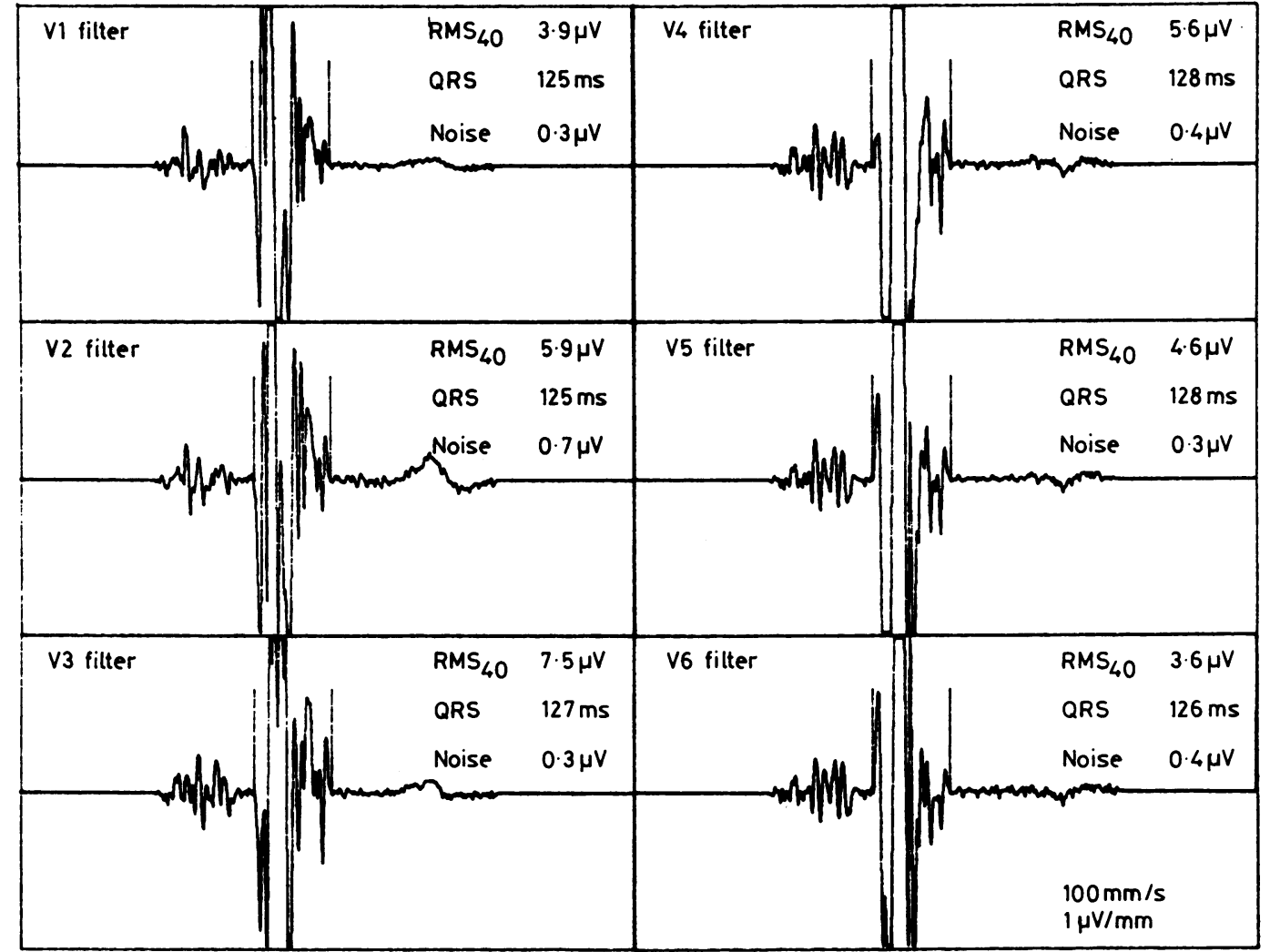

late potentials between patients in whom reperfusion was successful or unsuccessful $(10.4 \% v$ $25 \cdot 0^{\circ}$ ) was not statistically significant ( $\mathrm{p}=$ $0 \cdot 11)$.

\section{Discussion}

This study indicates that patients treated with thrombolytic agents within four hours of an acute myocardial infarction are "protected" from the increase in the frequency of late potentials that occurs in patients not treated by thrombolysis. Irwin et al and Volosin et al reported that late potentials that presented within a few hours of acute myocardial infarction regressed within seven days of successful reperfusion. ${ }^{910}$ The difference with our observations may reflect differences in methods. Both groups ${ }^{910}$ performed the first signal averaged electrocardiogram earlier than we did, at a time when dynamic changes in the border zone of the acute myocardial infarction are likely. In addition, Irwin et al used RMS $_{40}$ $\leqslant 25 \mu \mathrm{V}$ as the sole criterion for late potentials, while criteria for late potentials were not reported by Volosin et al. ${ }^{10}$ Like us, Gang et al found a reduced incidence of late potentials among successfully reperfused patients. ${ }^{11}$

To detect late potentials we averaged 12 electrocardiogram leads filtered at a cut off of $60 \mathrm{~Hz}$ by a non-recursive digital filter. This method differs from Simson's technique, which is based on the orthogonal (XYZ) lead system, with a bidirectional filter at a cut off of $40 \mathrm{~Hz}$. Our own (unpublished) data and those of others ${ }^{1213}$ show a comparable or higher detection of late potentials with a multilead rather than a composite $X Y Z$ vector. A $60 \mathrm{~Hz}$ cut off is within the accepted range of filters used for the detection of late potentials. ${ }^{14} \mathrm{We}$ sought an abnormal $\mathrm{RMS}_{40}$ and QRS duration in two adjacent leads because we had never found these two features in two or more adjacent leads in healthy individuals.

Our study indicates that thrombolytic treatment may enhance electrical stability, as reflected by the decreased frequency of late potentials. The present study does not establish whether this is an independent effect on the ventricular electrical characteristics or a result of enhanced myocardial salvage (shown by the higher left ventricular ejection fraction after successful reperfusion). This would require a long term study. Several studies showed fewer spontaneous severe arrhythmias and less inducibility of ventricular tachycardia by programmed ventricular stimulation in patients who had undergone thrombolytic treatment. $^{15-17}$ Our data accord with these observations of increased electrical stability, which may be partly responsible for the enhanced survival of patients who undergo thrombolytic treatment for acute myocardial infarction.

This work was supported by a grant from the Chief Scientist, Ministry of Health, Israel.

1 Ideker RE, Mirvis DM, Smith WM. Late, fractionated potentials. Am J Cardiol 1985;55:1614-21.

2 Breithardt G, Borggrefe M. Recent advances in the identification of patients at risk of ventricular tachyarrhythmias: role of ventricular late potentials. Circulation 1987;75: 1091-6.

3 Gruppo Italiano per lo Studio della Streptochinasi nell' Infarto Miocardico (GISSI). Long term effects of intravenous thrombolysis in acute myocardial infarction: intravenous thrombolysis in acute myocardial infarction:

final report of the GISSI Study. Lancet 1987;ii:871-4.
4 ISIS-2 Collaborative Group. Randomized trial of intraviS-2 Collaborative Group. Randomized trial of intra-
venous streptokinase, oral aspirin, both, or neither among venous streptokinase, oral aspirin, both, or neither among
17,187 cases of suspected acute myocardial infarction: 17,187 cases of suspected acu

5 White HD, Norris RM, Brown MA, et al. Effect of intravenous streptokinase on left ventricular function and 
early survival after acute myocardial infarction. $N$ Engl $J$ Med 1987;317:850-5.

6 The I.S.A.M. Study Group. A prospective trial of intravenous streptokinase in acute myocardial infarction (I.S.A.M.); mortality, morbidity, and infarct size at 21 days. N Engl J Med 1986;314:1465-71.

7 Abboud S, Belhassen B, Laniado S, Sadeh D. Non invasive recording of the ventricular activity using an advanced method in patients with a damaged mass of ventricular method in patients with a damaged mass
tissue. $J$ Electrocardiol 1983;16:245-52.

$8 \mathrm{McNemar} Q$. Note on the sampling error of the difference between correlated proportions or percentages. Psychometrika 1947;12:153-7.

9 Irwin JM, Smith PM, Stack RS, Califf RM, Prystowsky EN. Successful reperfusion of infarcting myocardium is associated with reversal of electrical predictors of sudden cardiac death [Abstract]. J Am Coll Cardiol 1988;11:183A.

10 Volosin KJ, Beauregard LA, Kurnik BK, Fabiszewski R, Waxman HL. Time course of ventricular late potential development after coronary reperfusion with tissue plasminogen activator [Abstract]. PACE 1989;12(suppl I): 636 .

11 Gang E, Lew AS, Hong M, et al. Decreased incidence of ventricular late potentials after successful thrombolytic ventricular late potentials after successful thrombolytic
therapy for acute myocardial infarction. $N$ Engl J Med
1989;321:712-6.

12 Berbari EJ, Friday KJ, Jackman WM, Hudgins P, Lazzara R. Precordial mapping of signal averaged late potentials
compared to XYZ leads [Abstract]. J Am Coll Cardiol 1986;7:127A.

13 Atwood JE, Myers J, Forbes S, et al. High frequency electrocardiography: an evaluation of lead placement and electrocardiography: an evaluation of lead plac

14 Gomes JA, Winters SL, Stewart D, Targonski A, Barreca P. Optimal band pass filters for the time-domain analysis of Optimal band pass filters for the time-domain analysis of the signal averagec

15 Sager PT, Perlmutter RA, Rosenfeld LE, McPherson CA Wackers FJ, Batsford WP. Electrophysiologic effects of thrombolytic therapy in patients with a transmural anterior myocardial infarction complicated by left ven tricular aneurysm formation. J Am Coll Cardiol 1988;12 19-24.

16 Kersschot IE, Brugada P, Ramentol M, et al. Effects of early reperfusion in acute myocardial infarction on arrhythmias induced by programmed stimulation: a prospective randomized study. J Am Coll Cardiol 1986;7:1234-42.

17 Vermeer F, Simoons ML, Lubsen J. Reduced frequency of ventricular fibrillation after early thrombolysis in myoventricular fibrillation after early throm
cardial infarction. Lancet 1986;i:1147-8. 